\title{
O neoliberalismo chileno (1973-1990) e seus desafios à integração sul-americana dos anos 1980
}

\section{Rafael Macedo da Rocha Santos ${ }^{I}$}

Resumo: O modelo econômico chileno adotado por Pinochet não encontrou similaridade de política econômica em nenhuma das demais ditaduras militares da América do Sul. O pioneiro do neoliberalismo chileno contribuiu para a formação pósredemocratização de um país com características distintas do restante da América Latina: um Chile cuja inserção em blocos regionais fora relativizada em prol de um alinhamento com potências como Japão, EUA e Europa. Nesse sentido, associamos o não-ingresso do Chile no Mercosul com essa política de afastamento do continente. $\mathrm{O}$ objetivo do artigo, portanto, é analisar as origens do modelo econômico chileno e sua relação com a integração.

Palavras-Chave: liberalismo, ditadura, blocos econômicos, América Latina.

\section{Chilean neoliberalism (1973-1990) and its challenges to South American integration in the 80's}

\begin{abstract}
The chilean economic model adopted by Pinochet did not find similar economic policy in any of the other military dictatorships in South America. The pioneer of chilean neoliberalism contributed to the post-redemocratization formation of a country with characteristics distinct from the rest of Latin America: a Chile whose insertion in regional blocks was relativized in favor of an alignment with powers like Japan, USA and Europe. In this sense, we associate non-entry into Mercosur with this policy of moving away from the continent. The purpose of the article is analyze the origins of chilean economic model.
\end{abstract}

Keywords: liberalism, dictatorship, economic blocs, Latin America.

Artigo recebido em 18/04/2018 e aprovado em 27/05/2018. 


\title{
O NEOLIBERALISMO CHILENO (1973-1990) E SEUS DESAFIOS À INTEGRAÇÃO SUL- AMERICANA DOS ANOS 1980
}

\author{
RAFAEL MACEDO DA ROCHA SANTOS
}

\section{Introdução}

Buscaremos nesse artigo demonstrar como o Chile adotou um caminho diferente daquele adotado pelo Brasil, por meio da análise das especificidades do modelo econômico chileno frente ao modelo sul-americano, as grandes diferenças entre a orientação da ditadura chilena e o restante dos regimes de exceção no continente e a incongruência da economia do país andino nos tratados de integração sul-americanos.

Queremos demonstrar comparativamente como o Chile trilhou um caminho completamente distinto ao percorrido pelo Brasil: Enquanto Brasília passaria a priorizar suas relações com a América Latina a partir do governo Geisel, o governo militar de Santiago se distanciava de certa forma do continente, preferindo seus laços diplomáticos e vínculos econômicos com outros países extra hemisféricos.

O foco dessa pesquisa consiste na histórica falta de coesão da América Latina: a falta de posições coordenadas e a ausência de convergência política e econômica têm sido uma antiga experiência na região e um fator que dificulta o processo de integração continental.

A utilização do método comparativo para abordar as semelhanças e diferenças é compreendida como a melhor forma de se estabelecer uma série de paralelos, aproximações e distinções entre as trajetórias percorridas pelas nações latinoamericanas.

Assim como na História Comparada, os processos de regionalização dependem de elementos comuns, interesses mútuos e objetivos compartilhados. A tentativa de criação de redes de interação capazes de privilegiar o coletivo em detrimento de interesses singulares relaciona a modalidade comparada cruzada de História aos fluxos de integração. A semelhança de suas estruturas políticas, suas economias e a grande relevância que cada uma das nações exerciam para o conjunto da América Latina eram fatores determinantes para o êxito do método comparativo.

\section{Teorias de Relações Internacionais:}

O liberalismo é a corrente das relações internacionais que pressupõe a existência de uma ordem internacional e foi personificado pelas ideias do presidente norte-americano Wilson, preconizador da formação de uma Liga de Nações no mesmo ano de fundação da cátedra de relações internacionais em Gales, Grã-Bretanha. Tais teóricos defendiam uma reforma conservadora dos mecanismos políticos-diplomáticos, democratização de novas instituições internacionais e a construção de uma paz duradoura. Os idealistas concebem a possibilidade de existência de uma "ordem mundial" harmoniosa e cooperativa.

A subordinação dos Estados aos preceitos neoliberais relativizou, segundo os autores defensores da ordem, o acirramento da ideia do iminente confronto de interesses entre as nações, como fora preconizado desde o século XIX. Propunha-se, a partir de então, a transferência de prioridades das relações inter-estatais para as relações entre os povos, fator que a priori reduziria as tensões causus belli, pois reduziria as atribuições nacionais. 


\section{O NEOLIBERALISMO CHILENO (1973-1990) E SEUS DESAFIOS À INTEGRAÇÃO SUL- AMERICANA DOS ANOS 1980}

\section{RAFAEL MACEDO DA ROCHA SANTOS}

A instauração da noção de ordem mundial, pressuposto do neoliberalismo, pelo contrário, supõe a homogeneização de diferenças e a formação de uma sociedade global com o intuito de evitar a ocorrência de situações de ameaças generalizadas à segurança coletiva. Tais ideias surgem como uma forma de consolidação e de manutenção de uma situação onde seus interesses enquanto potência dominante não estivesse em risco.

A existência de um sistema de Estados, que constituem em si uma sociedade sem governos ou autoridade suprema ou legítima, são características marcantes das relações internacionais. A ordem internacional, no entanto, sugere a existência de Estados a partir da interação e da coexistência entre seus membros.

Alexander Zhebit ${ }^{\mathrm{II}}$ questiona o conceito de anarquia das relações internacionais: segundo o autor, tal noção torna-se relativa quando se expõe que o entorno do Estado e da associação entre esses, estaria mais consistente com formas reguladas de interação e estabilidade. A existência de uma nova ordem mundial diminui a visão clássica de anarquia e institui, por exemplo, noções de moral, de sociabilidade e de respeito às direitos humanos e aos princípios democráticos nas relações entre os Estados.

O conceito de "ordem mundial" nas relações entre os Estados ganha pertinência na medida que a pressão da comunidade internacional pelo respeito aos acordos cumpridos. Tal noção se baseia na crença de que a convivência e a integração entre as nações são possíveis apesar do conceito anárquico que tangem as relações internacionais. Partindo de um conceito maquiavélico, segundo José Guilhon Albuquerque:

\footnotetext{
A ordem política estável só é possível porque existe uma autoridade suprema que deriva da necessidade de superar a natureza intrinsecamente conflituosa da sociedade. E essa autoridade suprema só é aceita pelas partes em conflito porque não apenas garante os grandes contra a ameaça de anarquia como também garante o povo contra a ameaça de opressão proveniente da ambição dos grandes. .II $^{\text {I }}$
}

Nesse sentido, questionam-se autores clássicos que basearam suas análises na natureza conflituosa do homem como, por exemplo, Tucídides. Ao analisar o caráter anárquico das relações internacionais e a inevitabilidade da guerra como parte da natureza humana, os realistas das relações internacionais não conceberam a convivência harmoniosa, os valores morais e o respeito ao direito internacional como possibilidades de doutrinas humanas. Os liberais por sua vez defenderam que o fato de que a ordem internacional seja anárquica não significa imprevisibilidade de ações e instabilidade.

Williams Gonçalves ${ }^{\mathrm{IV}}$ define política externa ou política exterior, em um sentido restrito, como "a atividade por intermédio da qual os Estados se relacionam entre si". Torna-se necessário portanto considerar que o "poder" efetivo de uma política externa está diretamente relacionado às capacidades materiais que o Estado dispõe como sua relevância geopolítica, grandeza territorial, econômica e militar. Dessa forma, seu alcance regional ou global resultaria do poder relativo que um país exerça em relação aos outros que formam o sistema internacional.

Um dos paradigmas mais elementares em termos de análise de política internacional diz respeito à forma como os Estados, componentes centrais do "sistema", atuam ou se posicionam em determinadas circunstâncias. A partir da noção básica de 


\section{O NEOLIBERALISMO CHILENO (1973-1990) E SEUS DESAFIOS À INTEGRAÇÃO SUL- AMERICANA DOS ANOS 1980}

\section{RAFAEL MACEDO DA ROCHA SANTOS}

que esses atores buscarão primordialmente sua existência enquanto Estado, os analistas internacionais buscam uma certa previsibilidade de como eles se comportarão em algumas conjunturas sempre levando-se em conta os dividendos que ganharão com tal alinhamento.

O esgotamento do modelo econômico baseado na intervenção estatal representou a ascensão do neoliberalismo, orientando as economias em geral a adotarem uma perspectiva de abertura de suas economias ao capital externo. Segundo Miriam Gomes Saraiva ${ }^{\mathrm{V}}$, o paradigma liberal passou a ser marco teórico para a orientação das políticas humanas desde os anos 1980.

\section{Os modelo econômicos chileno e brasileiro}

Grande parte das receitas externas adquiridas pelo Chile provinha do comércio de cobre com os países ricos, principal pauta de exportação de Santiago. A economia interna nos anos Pinochet, portanto, estava atrelada ao comércio exterior, confiando na ideia de construir um polo confiável de fornecimento de matérias-primas para os países ricos. A grande e histórica dependência chilena do cobre, comprado, sobretudo, pelos países ricos e que eram responsáveis por $60 \%$ de todas as suas receitas, colocavam essas relações para a política externa como prioridades na frente de qualquer outra.

A legislação do país andino havia facilitado a exploração dos recursos naturais chilenos ao longo da História por países extra hemisféricos. $\mathrm{O}$ baixo custo das extrações de cobre, os impostos mais baratos e acessíveis do que no restante da América Latina e a existência de uma burocracia menos atuante contribuíram para que o Chile surgisse como um polo atrativo de investimentos maior em comparação com os seus vizinhos.

O golpe militar de setembro de 1973, que empossou o Comandante do Exército Augusto Pinochet na presidência da nação, representou uma reação conservadora às medidas estatizantes de cunho marxista adotadas pelo líder deposto Salvador Allende. A vivência de governo pioneira adotada por Allende merecia uma contrapartida: um regime militar bem peculiar na região, responsável por uma completa reconfiguração do país.

A concentração das ações de governo sobre Augusto Pinochet, apesar de "oficialmente" haver o predomínio de uma Junta Militar composta pelo chefe das três Forças Armadas. Diferentemente das ditaduras brasileira e argentina, que tinham certo mandato para seus presidentes generais (ou alguma rotatividade no poder), a ditadura chilena se concentraria excessivamente nas mãos de Pinochet.

Segundo Heraldo Munhoz ${ }^{\mathrm{VI}}$, o Chile seria apenas uma ditadura a mais na região, não fosse a importância do modelo econômico pioneiro adotado por Pinochet. $\mathrm{O}$ pequeno país andino, ao longo dos anos 1970 e 1980, serviu como um "laboratório" para as experiências neoliberais adotadas por praticamente todos os países do mundo a partir dos anos 1990. Isso permitiu que Santiago se sobressaísse como um modelo de desenvolvimento econômico único na região e que seria decisivo para uma arrojada e peculiar inserção internacional do país inclusive após os 17 anos de ditadura (19731990). 


\section{O NEOLIBERALISMO CHILENO (1973-1990) E SEUS DESAFIOS À INTEGRAÇÃO SUL- AMERICANA DOS ANOS 1980}

\section{RAFAEL MACEDO DA ROCHA SANTOS}

Em termos de política econômica, Guy Sorman reflete o legado do governo militar chileno:

\footnotetext{
"los años de Pinochet no fueron pues solamente uma revolución econômica, la instauración del único capitalismo auténtico de América Latina, sino del mismo modo una revolución: la libertad econômica como prévia condición para el ejercício verdadero de la libertad política"VII .
}

Nesse sentido, Pinochet tentou conciliar um autoritarismo político com as práticas de neoliberalismo ditadas pelos "Chicago Boys "VIII.

Os neoliberais chilenos conseguiram reduzir decisivamente o tamanho e as funções do Estado, eliminando qualquer obstáculo à "liberdade do capital". As transnacionais e os monopólios estrangeiros receberam vários estímulos para aportarem capitais no país.

O grande ajuste promovido por Pinochet permitiu preparar as bases para uma "Revolução Econômica": nesse sentido, o governo militar desvalorizou a moeda do país para que os exportadores de seu país obtivessem receitas externas suficientes para o financiamento e abriu a economia do país, reduzindo as alíquotas de importação e exportação, apesar de que isso significasse à curto prazo um empobrecimento acentuado, resultado da grande redução do poder de compra da população.

A ditadura abriu o mercado interno para as importações, ofereceu subsídios para que estrangeiros (oriundos de países ricos, sobretudo) adquirissem desde o controle de bancos até, companhias elétricas, desmantelando todas as estruturas construídas pelos antigos governos, entre eles as fortes pressões e demandas populares exercidas sobre o governo.

O modelo econômico chileno que fora adotado por Pinochet distinguia-se das demais economias sul-americanas. Na verdade, pressuponha-se o contrário do que fora implementado pela ditadura militar desenvolvimentista do Brasil: o esvaziamento das funções estatais em detrimento do ingresso de um grande volume de capitais externos.

Enquanto Brasília adotava um processo de desenvolvimento baseado na intervenção do Estado na condução da vida econômica, Santiago, desde 1973, promovia a abertura da economia chilena, por meio de um processo maciço de privatizações de praticamente todos os setores sociais. Antes do golpe de 1973, o Estado respondia por $60 \%$ do PIB chileno, enquanto a partir dos anos de Pinochet, esse número cairia para cerca de $15 \%$.

Já o Brasil a partir dos anos 1980 buscaria a consolidação de novas posturas mais coerentes como o fim do alinhamento automático com os EUA, a aproximação com o Terceiro Mundo e o estreitamento de vínculos com os vizinhos como novas vertentes orientadoras das inserções internacionais brasileiras. Dessa forma, o Brasil buscava se aproximar da América Latina mais efetivamente, estreitando laços comerciais necessários à eliminação da dependência excessiva dos mercados "protecionistas" do norte, totalmente diferente da postura diplomática chilena.

Desde o governo Ernesto Geisel (1974-1979), já se havia em mente a necessidade do Brasil em promover um desenvolvimento autônomo e regional em todos os aspectos. Esta autonomia passava inerentemente pela aproximação com seus vizinhos sul-americanos, o que seria uma constante a partir dos anos 1980. 


\section{O NEOLIBERALISMO CHILENO (1973-1990) E SEUS DESAFIOS À INTEGRAÇÃO SUL- AMERICANA DOS ANOS 1980}

\section{RAFAEL MACEDO DA ROCHA SANTOS}

Com o fim do AI-5, a política externa brasileira deixaria de estar atrelada aos estudos geopolíticos das escolas militares e se associaria as potencialidades econômicas internas do país e suas oportunidades de inserção e projeção internacional. Nesse momento, o Brasil passa a adotar uma postura de globalismo em substituição ao americanismo.

A exaustão do modelo desenvolvimentista, o esgotamento dos regimes autoritários, os aumentos dos preços de petróleo além da política hostil das nações desenvolvidas podem ser apontados como fatores determinantes para uma redefinição de alianças regionais. Nesse sentido, diferente do Chile, Brasília passou a redirecionar suas vendas para o próprio continente como uma forma de fazer frente à sua crescente dívida externa.

Vários críticos afirmam que Chile não se industrializou com a força do Brasil e se manteve como um "mero" fornecedor de matérias-primas, a maioria delas de baixo valor agregado. A política de substituição de importações que fora implementada pelas demais ditaduras do continente não fora seguida pelo Chile, que priorizou uma abertura comercial, a partir da adoção de reduzidas tarifas alfandegárias. A proteção do mercado interno fora abolida e o Chile pôde se integrar ao mundo com uma típica "economia de mercado" legitimada pela grande repressão interna conduzida pelo regime militar.

O governo de Santiago, desde 1973, promovia a abertura da economia chilena, por meio de um processo maciço de privatizações de praticamente todos os setores sociais. Antes do golpe de 1973, o Estado respondia por $60 \%$ do PIB chileno, enquanto a partir dos anos de Pinochet, esse número cairia drasticamente, para cerca de $15 \%$.

Para os seus defensores, a política econômica chilena ficara conhecida como o "Milagre Chileno", responsável pela completa liberalização e desregulamentação da economia, na contramão das demais economias sul-americanas como o Brasil. Os gastos públicos diminuíram $20 \%$ enquanto foram cortadas várias formas de obtenção de crédito.

Por conta da orientação neoliberal de seu governo, o governo Pinochet pautou seu projeto de política externa excessivamente na "necessidade" (urgente, diga-se de passagem) de liberalização do comércio mundial. Todas as suas inserções internacionais estavam atreladas à essa noção, daí, a dificuldade de inserção do Chile em blocos regionais, que na visão dos chilenos, estas associações restringiam seu raio de atuação. Os acordos regionais como a ALALC não ofereciam como contrapartida tarifas alfandegárias flexíveis para que a política externa de Santiago pudesse se inserir plenamente como membro efetivo dos blocos da América Latina.

Desde o golpe de 1973, Santiago desenvolveu um projeto de política externa baseado em TLCs (Tratados de Livre Comércio), sem tanta ênfase no regionalismo e com um "olhar especial para os Estados Unidos". A grande ênfase chilena no livrecomércio, a todo custo representou a preferência por um "regionalismo aberto", concomitante à aproximação com outros polos de poder extra regionais.

Para os críticos latino-americanos do modelo econômico neoliberal de Pinochet, entretanto Chile "renunció a luchar por constituirse en un país desarrollado industrial moderno y prefirió mantenerse estático, priorizando la exportación de matérias primas y la dócil asociación con los mercados de norte",IX. 


\section{O NEOLIBERALISMO CHILENO (1973-1990) E SEUS DESAFIOS À INTEGRAÇÃO SUL- AMERICANA DOS ANOS 1980}

\section{RAFAEL MACEDO DA ROCHA SANTOS}

Uma das grandes diferenças entre o novo governo autoritário chileno e os demais regimes militares continentais, entretanto, consistia no grande aparato repressivo sem comparativo exercido por Pinochet, que centralizava todas as atenções em sua figura e impedia a ascensão, até mesmo nas Forças Armadas, de quadros que poderiam sucedê-lo (como acontecera nas ditaduras brasileira e argentina).

Nesse sentido, a América Latina não surgia como uma prioridade acima de tudo, como ocorria no Brasil, mas como parte integrante de outras inserções internacionais de Santiago, por vezes, com a mesma importância atribuída aos seus vizinhos. A formação de zonas de livre-comércio bilaterais (país a país), sem tanta ênfase no conjunto da América Latina, era compreendida pelos membros formuladores de política externa do governo Pinochet como a melhor forma para determinar as inserções internacionais do país. Tal posicionamento estaria atrelado mais às necessidades comerciais do país do que propriamente a interesses diplomáticos ou culturais do país, como ocorria no Brasil.

As relações chilenas com a América Latina eram circunstanciais. Nesse sentido, o governo chileno preferia negociar tratados comerciais separadamente, com cada país que lhe fosse conveniente, ao invés de pleitear um processo regional amplo e abrangente.

As tarifas alfandegárias chilenas eram incompatíveis com o protecionismo dos seus vizinhos. Nessa conta, pesava também o fato de que a América Latina não demandasse grandes quantidades de cobre. Somente para efeitos de comparação, Santiago no início dos anos 80 , exportava somente $20 \%$ de toda a produção desse produto para o continente e adquiria receitas muito menores com o comércio regional do que o Brasil, por exemplo.

Em relação às doutrinas de inserção internacional do país e quanto às prioridades da política externa do Chile a partir de 1973, o governo Augusto Pinochet inaugurou uma tendência que seria seguida mesmo após o final do seu regime em 1990. Tal orientação estava praticamente integrada com a política econômica neoliberal adotada internamente. Apesar de o Chile valorizar suas relações continentais, elas estavam, inseridas em um contexto maior (ou por muitas vezes secundários), visto que outras prioridades de fora do continente ocupavam o espaço deixado pelos latino-americanos.

Tal visão parte da premissa de que o ingresso do Chile, como qualquer outro membro de acordos regionais como a ALADI e a ALALC, não eram compatíveis com as altas tarifas alfandegárias cobradas pelos vizinhos e com a grande burocracia no comércio exterior dos países latino-americanos, visto pelos chilenos, por vezes, mais como concorrentes do que como complementares. A falta de políticas compensatórias no comércio regional levava o Chile a adotar políticas isoladas do continente. Por esses fatores, para Pinochet, a proximidade geográfica não se configurava como um diferencial decisivo para que o regime militar as priorizasse em detrimento de outros alinhamentos.

Na visão do Chile, a construção de um espaço comum econômico dependia da redução de tarifas alfandegárias e no ajuste das políticas internas dos países promotores da cooperação regional. $\mathrm{O}$ interesse chileno em combater as distorções econômicas e os desequilíbrios no continente era a única forma de promoção de uma união aduaneira, requisito para o advento de uma integração econômica "plena". 


\section{O NEOLIBERALISMO CHILENO (1973-1990) E SEUS DESAFIOS À INTEGRAÇÃO SUL- AMERICANA DOS ANOS 1980}

\section{RAFAEL MACEDO DA ROCHA SANTOS}

O grande problema, entretanto, consistia na regulação do capital estrangeiro que o modelo de integração sul-americano pressuponha e que o modelo econômico do Chile condenava. Aliado a isso, soma-se o fluxo desigual de capitais no interior do continente e a falta de coordenação das políticas macroeconômicas na região. Dessa forma, a integração do país andino à comunidade regional não oferecia vantagens imediatas.

De acordo com Hector Rojas ${ }^{\mathrm{X}}$, os preços dos produtos chilenos foram atrelados aos preços deles no mercado internacional. Se a liberdade política e de expressão não pôde ser praticada, a liberdade econômica fora amplamente exercida. Nenhum tipo de intervenção estatal fora aprofundada, a não ser pela privatização de cerca de 600 empresas do governo entre 1973 e 1983 e por mais 538 entre 1983 e 1990.

O Chile, como exemplo de país pequeno, procurou comportar-se entre a segunda metade dos anos 1970 e ao longo dos anos 1980 como um "Estado comercial" (trading state). A importância de seus laços econômicos com os Estados Unidos e a Europa sobrepunha-se sobre a valorização de suas relações sul-americanas. A política ortodoxa do livre-comércio seria responsável pela deserção do país nas relações regionais na visão de Norberto Consani do IRI/UNLP: "a partir de 1973, Chile deja de participar activamente en el proceso de integración económica regional negociada y adopta um régimen más libre de tipo de cámbio diferente del continente"XI.

As dificuldades de inserção de uma economia neoliberal em um contexto econômico continental de intervenção estatal dificultavam o diálogo entre o Chile e as demais nações latino-americanas. A retirada voluntária do Chile do Comunidade Andina de Nações em 1976 exemplifica essa hipótese. Naquela ocasião, a aprovação de uma Resolução ("Decisão 24") que limitava a entrada de capitais estrangeiros e estipulava especificações e grande controle sobre propriedades de empresas multinacionais de fora do bloco andino fora decisiva para que Pinochet se retirasse unilateralmente do acordo.

\section{Conclusão:}

O Chile sempre condicionou os intercâmbios regionais às variações de ofertas de seus produtos para outros países como EUA, Europa e países do Pacífico. Isso fora responsável pelo atrelamento da economia chilena aos polos de poder do norte, em comparação com os níveis de vinculação que eram apresentados pelos demais países latino-americanos. Somente para efeitos comparativos, em 1979, enquanto a carga tributária no Chile alcançava a cifra de $20 \%$ do PIB, no Brasil alcançava quase $45 \%$, evidenciando assim o tamanho de cada Estado na economia.

Nesse sentido, destacamos a histórica associação chilena com os países da Ásia e do Pacífico, (nações com avançada industrialização e de grande demanda por matériasprimas chilenas como o Japão). Diversos produtos como cobre, iodo, frutas e pescados eram tradicionalmente bem "recebidos" nesses mercados. A larga costa chilena, voltada para o Pacífico, contribuía para que Santiago se voltasse para essas regiões, concomitantemente ou paralelamente à América Latina.

Nesses alinhamentos, ainda devem ser levados em conta capitais japoneses, norte-americanos e europeus que estavam depositados na economia chilena 


\section{O NEOLIBERALISMO CHILENO (1973-1990) E SEUS DESAFIOS À INTEGRAÇÃO SUL- AMERICANA DOS ANOS 1980}

\section{RAFAEL MACEDO DA ROCHA SANTOS}

(ingressantes por meio do processo de privatizações) e que se associavam para fazer a economia do país "sobrevivesse" durante a crise dos anos 1980. Esta associação estava ligada em todos os aspectos, ligando inclusive as orientações de política externa do país a essas tendências de convergência para as doutrinas estabelecidas pelo Primeiro Mundo.

O projeto de Pinochet para a economia chilena pressuponha um grande arrocho salarial, grande desvalorização da moeda e do poder de compra, que contribuiu para um empobrecimento da população a níveis radicais, o que seria responsável pela persistência de cerca de $45 \%$ da população abaixo da linha da pobreza, resultado do corte de praticamente todos os benefícios sociais concedidos pelo Estado.

O modelo econômico chileno era naturalmente bem conceituado pelas potências do norte. Na Grã-Bretanha, o governo Thatcher implementava um modelo semelhante ao de Pinochet, criando uma convergência econômica que teria frutos nos anos seguintes, pois criou a ideia de Santiago como único "porto seguro" e "aliado confiável" na América Latina diante de um conjunto de "países economicamente instáveis". Vale lembrar nesse mesmo contexto que os chilenos apoiaram os britânicos na guerra das Malvinas (1982) enquanto todo o continente apoiava a causa argentina.

\section{Notas}

\footnotetext{
${ }^{\text {I }}$ Doutorando em História Comparada pela UFRJ. Especialista em História e Relações Internacionais. Contato: rafaelmrsantos@yahoo.com.br. Esse artigo contou com apoio e financiamento da CAPES.

II ZHEBIT, Alexander. Ordens e Pacis. Rio de Janeiro: FAPERJ, 2008. p. 25.

III ALBUQUERQUE, José Guilhon. Relações Internacionais Contemporâneas: a ordem mundial depois da guerra fria. Petrópolis: Vozes: 2005. p. 23.

IV GONÇALVES, Williams. Argentina e Brasil: Vencendo preconceitos. Rio de Janeiro: Revan, 2010. V SARAIVA, Miriam Gomes. As estratégias de cooperação sul-sul nos marcos da política externa brasileira. Revista Brasileira de Política Internacional: volume 50, $\mathrm{n}^{\circ}$ 2, 2007.

V SARAIVA, Miriam Gomes. As estratégias de cooperação sul-sul nos marcos da política externa brasileira. Revista Brasileira de Política Internacional: volume 50, nº 2, 2007.

${ }^{V I}$ MUÑOZ, Heraldo. Latin American Nations in World Politics. Santiago: Universitarias, 1984.

VII SORMAN, Guy. Economics don't lie. Londres: Pan Books, 1992.

VIII Informações extraídas da Revista brasileira Veja de 26 de setembro de 1973, edição 264. p.54.

IX CADERMATORI, José. Chile: El Modelo Neoliberal. Santiago: ChileAmérica CESOC, 1998, p.76.

${ }^{X}$ ROJAS, Hector. Chile, El país de futuro? Santiago: ChileAmérica CESOC, 1997.

XI CONSANI, Norberto (org.). Las relaciones internacionales de Argentina, Chile y México. Buenos Aires: Latinoamericana, 2007.
}

\section{Referências Bibliográficas:}

BANDEIRA, Luiz Alberto Moniz. O Eixo Argentina-Brasil: O Processo de Integração da América Latina. Brasília: UnB, 1987.

CAMARGO,Sônia.O universalismo do governo Figueiredo.São Paulo:Convívio, 1988.

CERVO, Amado. Relações Internacionais da América Latina. Brasília: Funag, 2001.

FIORI, José Luís. O mito do colapso do poder americano. São Paulo: Record, 2008.

GOMA, Oscar. Hacia un Chile Competitivo. Santiago: Editorial Universitarias, 2003. 
O NEOLIBERALISMO CHILENO (1973-1990) E SEUS DESAFIOS À INTEGRAÇÃO SULAMERICANA DOS ANOS 1980

RAFAEL MACEDO DA ROCHA SANTOS

LACOSTE, Pablo. La imagen del outro en las relaciones de la Argentina y Chile (1534-2000). Santiago, Universidad de Santiago, 2000.

LANUS, Juan. De Chapueltec al Beagle. Buenos Aires: Hyspamerica, 1986.

RUSSEL, Roberto e TOKATLIAN, Juan. A América Latina e suas opções estratégicas frente aos Estados Unidos. Revista de Política Internacional, volume 16, $\mathrm{n}^{\mathrm{o}} 3,2008$.

VIZENTINI, Paulo Fagundes (org.). A Grande Crise: a nova (des) ordem internacional dos anos 80 aos 90 . Petrópolis: Vozes, 1992. 